\title{
Development and Microbiology
}

\author{
Aja Watkins
}

Received: December 12, 2020 / Accepted: June 10, 2021

\begin{abstract}
On the basis of findings from developmental biology, some researchers have argued that evolutionary theory needs to be significantly updated. Advocates of such a "developmental update" have, among other things, suggested that we need to re-conceptualize units of selection, that we should expand our view of inheritance to include environmental as well as genetic and epigenetic factors, that we should think of organisms and their environment as involved in reciprocal causation, and that we should reevaluate the rates of evolutionary change. However, many of these same conclusions could be reached on the basis of other evidence, namely from microbiology. In this paper, I ask why microbiological evidence has not had a similarly large influence on calls to update biological theory, and argue that there is no principled reason to focus on developmental as opposed to microbiological evidence in support of these revisions to evolutionary theory. I suggest that the focus on developmental biology is more likely attributable to historical accident. I will also discuss some possible room for overlap between developmental and microbiology, despite the historical separation of these two subdisciplines.
\end{abstract}

Keywords microbiology · developmental biology · units of selection · inheritance $\cdot$ reciprocal causation · evolutionary rates

\section{Introduction}

Developmental biological evidence has provided the impetus for some scholars to argue that biological theory, and evolutionary theory in particular, is in need of revision. Developmental biologists have, among other things, shown that the relationship between genes and phenotypes is rather more complicated than

Aja Watkins

Boston University

E-mail: ajawatki@bu.edu 
a one-to-one correspondence, and have demonstrated the importance of epigenetic factors, including in patterns of inheritance. By contrast, the received view of evolutionary biology prioritizes genes as the vehicles for inheritance and as the causes of phenotypes. Developmental systems theorists, for example, as well as advocates for an Extended Evolutionary Synthesis, have argued that this received view should be updated to account for developmental biological evidence.

However, what has gone largely unnoticed by proponents of such a theoretical update is that evidence from microbiology, not just developmental biology, supports many of the same revisions. In this paper, I focus on four of them, relating to: (1) units of selection, (2) modes of inheritance, (3) reciprocal causation, and (4) rates of evolution. On each of these four topics, I will argue, developmental biology and microbiology are in agreement about the changes to canonical evolutionary theory that are called for.

Ultimately, this paper seeks to answer the question: why hasn't microbiology had a greater impact on evolutionary theory? Of course, microbiology has had a very large impact, especially resulting from advances in molecular biology. But, I suggest, it could have been larger; microbiological evidence could have been (and still could be) used to argue for some revisions to evolutionary theory, in line with the revisions for which those focusing on developmental biology have advocated. My thesis is that there is no in-principle reason why a call for these revisions has been based on developmental biological evidence, rather than microbiological evidence. To be clear, I will not be claiming that developmental update proponents have insufficient evidence for their claims, but that a focus on development per se is not necessary to motivate these theoretical claims. Accordingly, the challenge that proponents of these revisions make to the received view of evolutionary biology is likely more systematic and wide-ranging than a focus on developmental biology alone would suggest.

The structure of the paper is as follows. First, in section 2, I will give an overview of microbiological research relevant to evolutionary theorizing, focusing on a subset of theoretical issues relevant to the topic of this paper. I will discuss ways in which microbiology has, historically, impacted biological theory, after which I will explain how current microbiological evidence provides support for a reevaluation of units of selection, modes of inheritance, reciprocal causation, and rates of evolution. Next, in sections 3 and 4, I will give a similar overview for developmental biology: I will show how some proponents of a "developmental update" have used evidence from developmental biology to argue for broad revisions to evolutionary theory. Many of the recommendations are the same as could be given based on microbiological evidence - especially pertaining to the four issues on which I focus herein - but, as I will show, proponents of a developmental update seldom utilize microbiological results.

Finally, in section 5, I will argue for the claim that there is no in-principle reason why a call for theoretical revisions has focused on developmental rather than microbiological evidence. I will suggest that it is more likely due to historical accident, and propose a few possible historical contingencies that might explain the disproportionate focus on developmental biology. I will close by 
offering some remarks on the possible overlap between developmental biology and microbiology, which are intended to indicate that these subdisciplines need not be as siloed as they lately have been.

\section{Microbiology and Biological Theory}

Microbiological research has historically been invaluable to evolutionary theorists. I will point out one particularly notable example, although there are certainly others.

Research in microbiology in the twentieth century transformed the study of phylogenetics. First of all, research on microorganisms revolutionized phylogenetic methods, specifically by contributing to an enormous amount of research in molecular biology and gene sequencing, and recognizing the potential that these techniques had for a more precise phylogenetics. Prior to these molecular methods, phylogenetic trees were largely based on morphological similarity, presumed to indicate homology and therefore common ancestry (this method is still frequently used in paleontology, especially when molecular evidence is scant). However, morphological similarity is at best only a very rough indicator of homology, so the resulting phylogenetic trees had a high associated degree of uncertainty. Furthermore, other problems such as which characters to focus on when measuring similarity/difference of two taxa caused the process of making phylogenetic trees to be overly subjective or researcher-specific. Methods which relied on molecular data, by contrast, used traits that were explicitly linked to inheritance (namely, genes) and which could be surveyed and quantified more methodically than morphological traits. Nowadays, of course, molecular methods are used for more than just microorganisms - these methods are used across all three domains to construct phylogenetic trees - but the methods were developed by microbiologists, using microbial life (for a detailed history, see Quammen 2018).

Second, using these molecular techniques, microbiologists provided evidence that there are three biological domains: eukarya, consisting of all of the meso-sized organisms with which we are accustomed (as well as many microbes), bacteria, and archaea. Woese and Fox (1977), Woese et al. (1978), and Woese et al. (1990) in particular showed that then-standard depictions of the tree of life consisting of five kingdoms or those which divided all life forms into either eukaryotes or prokaryotes were both insufficient, and suggested adding a higher taxonomic level of "domain." Perhaps surprisingly, Woese et al. (1990) argued on the basis of molecular evidence (specifically, rRNA sequencing) that the split between bacteria and the other domains occurred before the split between eukarya and archaea, implying that prokaryotes did not form a monophyletic group. Note that, more recently, Cox et al. (2008) have provided a substantially different tree than Woese et al.'s, although both trees have the aforementioned implications for the history of life and for taxonomy.

These contributions to biological practice and theory are based largely on advances within molecular biology. Microorganisms are particularly easy to 
utilize to study molecular biology, and therefore were crucial in making the advances enumerated in the preceding paragraphs. However, microbiology is not reducible to molecular biology. Indeed, microbiology involves the study of more than two biological domains (all archaea and bacteria, as well as any microscopic eukaryotes). It therefore wouldn't be surprising if microbiology had even wider-ranging implications for evolutionary theorizing. Yet, as I will argue, many of the implications of microbiology haven't been taken up by evolutionary theorists - or, when those implications have been taken up, it has been on the basis of developmental, rather than microbiological evidence.

I am not the first to claim that microbiology has been neglected in biological theorizing (e.g., O'Malley and Parke 2020). Human scientists and philosophers alike have a bias for studying medium-sized phenomena. I suspect that this bias, among other factors, has led those interested in an update to evolutionary theory to focus so much of their attention on research in developmental biology in particular. Rather, as I will show, they could just as well have looked to significant microbiological research in support of the same theoretical claims.

The following subsections each deal with one topic for which the implications of developmental biological and microbiological research are similar. These topics are: units of selection (section 2.1), modes of inheritance (section 2.2 ), reciprocal causation (section 2.3), and rates of evolutionary change (section 2.4). I will first address the microbiological support regarding these topics, returning to a discussion of the relevant developmental biological evidence in section 4 .

\subsection{Units of Selection}

The debate in evolutionary biology regarding units of selection is usually about how different levels of selection interact or conflict: genes, cells, organisms, populations, species (Okasha, 2006; Lloyd, 2020). A close examination of microbiological research has led at least some theoretical biologists and philosophers of biology to reconsider this debate, a suggestion which has not been taken up in mainstream biology. Several insights from microbiology are important here.

First, microorganisms often serve as symbionts in relation to larger organisms. According to O'Malley (2014), this is also the most obvious way to relate microbiology to developmental biology: microbial symbionts affect the development of their hosts. She supports this with several examples: "Gut microbes influence the development of the animal gut; arthropod and nematode reproductive systems develop in dependence on bacterial Wolbachia and endosymbionts; the light organ of the squid, Euprymna scolopes, develops dramatically in response to colonization by Vibrio bacteria; rhizobia affect the development of plant root nodules" (p. 118). Noticing the tight relationship between microbial symbionts and their macrobial hosts may get us to rethink what the appropriate units of selection are. Especially in cases of obligate symbiosis, where neither the microorganisms nor the hosts can survive (or, perhaps, reproduce) without the aid of the other, it seems misguided to think 
of natural selection acting on individual organisms as units of selection; rather, collectives consisting of symbionts can be said to co-evolve.

However, note that O'Malley (2014) does not think that bacterial processes are merely environmental factors in the development of multicellular organisms - the microorganisms themselves develop according to these interactions (p. 119). As we will see in section 4 , many developmental biologists are happy to analyze microorganisms as developmental resources, but rarely consider them as developing entities in their own right. I will attempt to point out this pattern throughout the paper, and return to a discussion of it at the end.

In the context of units of selection, microbiologists might point out that the problem with symbiosis runs even deeper, due to the importance of endosymbiosis or symbiogenesis. Endosymbiosis is literally when one symbiont lives inside of another (its host), but the term is usually used to refer to a specific set of crucial evolutionary moments, first argued for by Margulis (1967), where microorganisms combined as symbionts to form entirely new types of cells: mitochondria became a stable element of many eukaryotic cells (including our own), and chloroplasts became an essential organelle in photosynthesizing organisms (e.g., plants). These organelles were originally free-living microbes, and now occupy an essential place in the cells of many organisms. Thus, to say that a single organism (for instance, one human) should count as the appropriate unit of selection is already to admit the importance of symbionts for defining the units of selection, since each cell of that organism contains endosymbionts. Therefore, even if we ignore cases of symbiosis between microbes and macrobes, the symbiosis within the cells of many organisms cannot be ignored, and has implications for what we take to be the units of selection.

Other than as pertains to symbiosis, there are other microbial examples that make deciding on an appropriate unit of selection rather difficult. Some well-known examples are slime molds and biofilms. Both are cases where a community of microorganisms seems to act as one "unit," although that unit has blurry boundaries and can grow or shrink by adding or subtracting members (including by reproduction of its member microorganisms). Basically, these cases show that sometimes aggregates of organisms, rather than individual organisms, are perhaps better suited to be considered units of selection.

One proposal for units of selection that has received relatively little philosophical or biological attention is that of holobionts (e.g., Guerrero et al. 2013; Richardson 2017, although cf. Skillings 2016). A holobiont is a unit that comprises a host and all of its symbionts, or, as in the case of slime molds and biofilms, an aggregate (see Doolittle and Booth 2017 for a discussion of holobionts that includes biofilms). There is far from any consensus about whether or when holobionts are useful as units of selection, and whether the holobiont concept is useful in this context likely depends on whether particular host-symbiont associations have a deep, evolutionary history or not. However, suffice it to say that holobionts have been proposed as alternative units of selection on the basis of microbiological evidence.

Therefore, there is ample microbiological evidence to recommend an update in the biological treatment of units of selection. 


\subsection{Modes of Inheritance}

Microbiology has also complicated the common notion of inheritance: that inheritance occurs between parent and offspring only, largely in the form of genetic material.

First, even within a gene-centric view of inheritance, microbial systems suggest that inheritance should not be thought of as an exclusively vertical process. Lateral gene transfer (LGT), which encompasses a variety of processes by which microorganisms exchange genetic material with one another (and sometimes with macroorganisms!), is likely a common phenomenon and one which is known to alter the evolutionary trajectory of microbial lineages. LGT implies, for example, that phylogenetic trees need not be strictly-branching, and could instead have a reticulate structure. (For a discussion of the theoretical implications of LGT, see O'Malley 2014, p. 80-85, 101-108.)

Second, symbiosis, including endosymbiosis, also recommends an updated account of modes of inheritance, because symbionts can be inherited. For instance, proponents of the holobiont view mentioned in the previous section often point to the fact that our microbiomes are inherited both vertically and horizontally to show that inheritance is rather more complicated than the standard picture allows. Inheritance of symbionts challenges not only the relative prevalence of vertical compared to horizontal inheritance, but is also an example of non-genetic material being inherited.

Third, some have taken evidence of directed mutagenesis in microorganisms as evidence for the inheritance of acquired characteristics. O'Malley (2014), for example, in chronicling the persistence of Lamarckism in interpretations of microbiology, notes that "discovering spontaneous mutations [in E. coli] far from demolished Lamarckian frameworks for microbial evolution" (p. 98). In large part, this is because of evidence for directed mutagenesis (also called "hypermutation" or "adaptive mutation"), wherein mutations occur not randomly but in response to environmental conditions. ${ }^{1}$ Most random mutations, at least in coding or regulatory regions, are bound to be deleterious, but directed mutations will not be. The inheritance of a directed mutation resembles a Lamarckian process of inheritance insofar as what is being inherited is acquired in response to environmental conditions.

Fourth, microorganisms themselves can serve as evidence that epigenetic inheritance systems are at play. Jablonka and Lamb (1995, 2005), who normally tend to focus on the developmental biology literature, in fact use many examples of epigenetics in microorganisms. For example, although Jablonka and Lamb (2005) focus much of their discussion of epigenetic inheritance on plants and animals, they also bring up cellular memory in bacteria (p. 119) and the inheritance of cellular structures in ciliates such as Paramecium (p. 121-122). In a sense, any discussion of epigenetics which involves a thorough description of various epigenetic processes will be bound to discuss microbial

1 See also experiments utilizing mutator strains, e.g. Sniegowski et al. (1997); thanks to Maureen O'Malley for this suggestion. 
cases, as microorganisms often serve as model organisms in experiments on intracellular processes (for more on microbes as models systems, see O'Malley et al. 2015; O'Malley and Parke 2018).

All of this is to say that one need not look at the processes involved in the development of multicellular organisms to see that an expanded view of inheritance is warranted. Evidence from microbiology indicates both that horizontal, as opposed to merely vertical, inheritance, as well as non-genetic inheritance, is common and of evolutionary importance.

\subsection{Reciprocal Causation}

Prior to any suggestion of a developmental update, the standard view about the causal relationship between environments and the organisms that inhabit them is that the environment exerts selective pressure on organisms and, perhaps, provides resources for the organisms. This causal account is unidirectional: the environment can, potentially, have a causal force on the organism. By contrast, bidirectional causation between organism and environment is called "reciprocal causation." Evidence from microbiology recommends a reciprocal causation relationship, by pointing out ways in which organisms can, to some extent, control their environment.

Microbiologists are well aware of the effect that microorganisms can have on their environments; indeed, the largest-scale environmental change of biotic origin that we know of, the so-called Great Oxidation Event of 2.4 billion years ago, was the result of cyanobacteria (e.g., Canfield 2005; Sessions et al. 2009; Gumsley et al. 2017; see O'Malley 2014, chpt. 1 for a discussion of the importance of this event for evolutionary transitions). Indeed, many of the Earth's biogeochemical cycles, including the carbon and nitrogen cycles, among others, are mediated by the metabolic behavior of microbes (e.g., Bitton 2005; Merchant and Helmann 2012; Rousk and Bengtson 2014). For example, Pajares and Ramos (2019) present the case that the prevalence of nitrogenfixing microorganisms in the ocean (which make ambient nitrogen available for biological use, in the form of ammonia) also control the carbon cycle, because nitrogen fixation affects rates of primary production in the ocean, and rates of primary production affect rates of carbon draw-down from the atmosphere into the surface waters, and ultimately carbon export to the sea floor. These various cycles are complex and interconnected, then, but for our purposes the point is that the behavior of microorganisms is affecting the environmental resources available to those same (or other) organisms. I suggest that this behavior of microorganisms be seen as an instance of niche construction, where organisms are influencing the conditions of their environment.

A further way in which microbes can participate in niche construction also occurs in the context of symbiosis or parasitism (although, as has been the case in other sections, it is not necessary to think of microbes merely as symbionts to reach the conclusion that they construct their environment, as is clear from the previous paragraph). In particular, microorganisms which inhabit a host 
often influence the host's behavior in ways that potentially benefit the microorganism residents. Wolbachia, a genus of parasitic microorganism which has infected a remarkably high proportion of insects (Taylor et al., 2018), is a prime example; as reviewed by $\mathrm{Bi}$ and Wang (2020), Wolbachia infections are known to cause change in reproductive strategy (e.g., Hurst et al. 1999; Knight 2001), but also possibly behaviors related to sleep, learning and memory, feeding, and aggression.

Thus, evidence from microbiology points to recognizing that organisms can exert a causal influence on their environments, as well as vice versa.

\subsection{Rates of Evolution}

Finally, evidence from microbiology has implications for the expected rates of evolution. The standard view on evolutionary rates is that they are controlled by the rate of mutation, which is (roughly) constant.

Primarily, the connection between microbiology and rates of evolution has to do with horizontal inheritance (see section 2.2). Contrary to the standard view, if inheritance can happen via horizontal modes, such as lateral gene transfer, then the rates of change of genes or of other horizontally-inherited traits will be faster than commonly recognized.

In her theory of endosymbiosis between the mitochondria and its host, Margulis recognized the possible implication for rates of evolution. Endosymbiosis is mostly accepted today to explain at least one of the major evolutionary transitions (cf. O'Malley and Powell 2016). Much less accepted to this day is Margulis and Sagan (2004)'s more recent argument that horizontal inheritance is largely responsible for speciation events in general. O'Malley (2014, p. 8384) also discusses the implications of lateral gene transfer for speciation. While it may seem far-fetched to argue that endosymbiosis or lateral gene transfer is the primary cause of speciation, these sudden evolutionary changes - sudden if compared to natural selection on random mutation - do call into question long-held assumptions about gradual change by random mutation, and should be investigated empirically.

Thus, an examination of microbiological evidence has led some to say that the prevalence of horizontal inheritance should increase the estimated rates of evolutionary change.

In this section, we have seen that, while microbiological research has had a great influence on biological theorizing over the last several decades, it has broader implications than have been taken up in mainstream biology. However, some biologists and others have drawn similar conclusions from results in developmental biology, arguing that these should enter into the mainstream - but they are not using microbiological evidence to make their case. In the 
next section, I will discuss their arguments, and the evidence they do use: from developmental biology.

\section{The Developmental Update}

In this section, I will elaborate on the various views associated with what I am calling the "developmental update:" the update for evolutionary theory called for on the basis of developmental biological evidence. I will focus especially on developmental systems theory; this view has received the most philosophical attention, and, as a rather extreme version of the views in favor of a developmental update, is useful for illustrative purposes. I will also discuss the Extended Evolutionary Synthesis as well as some neighboring views of several other influential developmental biologists. The purpose of this section will be to demonstrate what proponents of the developmental update are advocating for, exactly.

Unlike the claims reviewed in section 2, which are rather disjoint, the developmental update has become a reasonably unified view of how biological theory should be updated (although, as we will see, there are some important disagreements). Therefore, unlike in my discussion of microbiology, I think it is useful to spend some time discussing the relationship between the various tenets of the developmental update, as well as the evidential basis for their claims, so that the reader can understand how the various pieces fit together. After providing a more general overview of the developmental update, I will focus individually on the same four issues as in section 2 - units of selection, modes of inheritance, reciprocal causation, and rates of evolution - in section 4 .

In what follows, I will be using a relatively broad concept of development, so I want to clarify it from the outset to prevent misunderstanding. Development is the process by which an organism has come to be what it is. This can involve physical growth from embryo to adult form, as is typically studied by many developmental biologists, but also learning (related to knowledge or behavior), senescence, and more. ${ }^{2}$ Part of what many proponents of a developmental update are pointing out is how ubiquitous developmental processes are, so, in order to speak their language I will utilize this broad view. Accordingly, many of the biologists who advocate for a developmental update base their work not just on developmental biology but on ethology, psychology, and more; for brevity, I will not distinguish these subdisciplines here. The main insight of developmental biology in the broad sense is that development is exceedingly complex: a whole host of factors (what some refer to as "developmental resources") affect development in interconnected ways, sometimes ways which are difficult to anticipate.

2 Others have used a narrower conception of development, one which only focuses on how the shape, size, structure, and anatomy of organisms, especially their morphological features, come to be. This is plausibly the result of a focus on the ontogeny of form in developmental biology. For narrower conceptions along these lines, see, e.g., Robert (2004); Love (2007, 2020). 
By contrast, the so-called "central dogma" of molecular biology, which says that information may travel from nucleic acid (DNA or RNA) to protein but not from protein to nucleic acid (Crick, 1958), is very linear. Views associated with the developmental update can be viewed as a response to the central dogma, insofar as they all reject this privileged position of genetic material as the only source of information; other developmental resources, developmental update proponents will say, are just as crucial. Various components of the developmental update also respond to related assumptions of classical evolutionary biology, such as the assumption that all inheritance is genetic, that heritable genetic variation is the primary source of phenotypic variation, and that macro-evolutionary patterns can be explained by appeal to changes in gene frequencies. This section will explicate the views of various proponents of the developmental update, including how these views hang together. As far as I know, a detailed account of the similarities and differences between these views does not exist elsewhere in the philosophical or biological literature.

I will start with developmental systems theory (DST), which has received the most philosophical attention. The ideas of DST were preceded by, among others, Kuo (1921, 1922, 1928, 1929, 1967), Carmichael (1925), Waddington (1941, 1942), McGraw (1946), Schneirla (1956), Lehrman (1953, 1970), Gottlieb (1970, 1976a,b, 1981), Wohlwill (1973), Lewontin (1974, 1982), Bateson (1978, 1983), Lerner (1978), and Levins and Lewontin (1985). ${ }^{3}$ Many of these researchers focused on developmental psychology and behavior, rather than embryology. Work on DST began in earnest with Oyama (1985). Oyama argues against the claim that genes encode information, which in turn gives instruction for the developmental process. She argues that genetic information is itself a product of development, and that rather than studying organisms as the product of genetic information acting based on environmental conditions (the standard, "interactionist" view) we should study entire developmental systems. Indeed, Oyama suggests that there is causal parity between genetic and environmental causes; this claim came to be known as the "parity thesis" of DST.

The next major innovation in DST came with Griffiths and Gray (1994), in which the authors argue that the parity thesis has several important implications for evolutionary theory. These authors were especially arguing against a "gene's eye" view of evolution (e.g., Dawkins 1976), connecting the critiques of the behavioral psychology tradition instantiated by Oyama to the rejection of the central dogma and other gene-centered views in evolutionary biology. First, Griffiths and Gray define the "developmental system" as all of "the resources that produce the developmental outcomes that are stably replicated" in a given lineage (p. 278). Second, they note that the replication of phenotypes from one generation to the next requires the replication of this entire developmental system, not just the genetic components of it (p. 283). One consequence of this view is that many factors outside of the organism itself,

\footnotetext{
3 For a more comprehensive history of DST, including more details on these early thinkers, see Johnston (2001, 2009), Gottlieb (2001), Lehrman (2001), and Griffiths and Tabery (2013).
} 
such as many features of its environment (e.g., nests, burrows, beaver dams, anthills), will be involved in and can be given an evolutionary explanation (p. 288). Third, Griffiths and Gray argue that DST recommends that life cycles - or, "a series of cycles of a developmental process" - be the primary unit of evolutionary analysis (p. 291); I will return to this view in more depth in section 4. Finally, Griffiths and Gray criticize the view that genes or DNA "self-replicate," suggesting instead both that DNA cannot self-replicate (i.e., without environmental input) and that all developmental processes replicate as part of the recurrence of a life cycle (p. 299-300).

The tenets of DST are usually represented as a list. ${ }^{4}$ I find it more illuminating to specify the logical and evidential relations between the tenets of DST, which I will now attempt to summarize.

DST takes seriously empirical evidence that development is contextual (the result of development depends on context), contingent (the results of development vary), constructive (development is a process requiring many inputs), and interactive (these inputs interact with one another to produce the developmental result). ${ }^{5}$ Constructivism and interactionism have led DST proponents to reject any metaphysical distinction between genetic and environmental causes, and, in turn, to reject the nature-nurture dichotomy (Ford and Lerner, 1992; Gray, 1992; Bateson, 2001; Oyama, 2002; Stotz, 2008). Importantly, though, DST theorists distance themselves from the standard kind of interactionism that maintains a genetic-environmental dichotomy, insofar as such a dichotomy implies that we could separate out the contributions of genetic from non-genetic causes (Oyama, 2002). Contextualism, contingency, constructivism, and interactionism, in combination, provide support for DST's aforementioned parity thesis: that all causal factors related to development are on a par (Ford and Lerner, 1992; Griffiths and Gray, 1994, 1997; Oyama, 2000, 2001; Shea, 2011; Griffiths, 2017).

The remainder of DST follows from the parity thesis. First and foremost, the parity thesis indicates that we should expand our focus to the entire developmental system, rather than individual organisms (certainly not just genes!). The developmental system includes the organism and all of the developmental resources involved in that organism's development, including all parts of its environment. Second, and consequently, DST theorists have, following Griffiths and Gray (1994), thereby re-conceptualized evolution as change in developmental systems, and, as a result of doing so, have argued for an expanded view of inheritance (e.g., Jablonka and Lamb 2005). Any developmental resource, including genes but also environmental factors, can be inherited (and can play the same role in evolution of any inherited factor, namely, to affect differential survival and reproduction), so there is naturally a strong connection between the view that a broad range of developmental resources must be considered and the view that inheritance is more extensive than just genetic

\footnotetext{
4 For instance, Gray (1992); Griffiths and Knight (1998); Godfrey-Smith (2000); Oyama et al. (2001); Robert et al. (2001); Stotz (2008); Johnston (2009); Pradeu (2010); Griffiths and Hochman (2015).

5 For some nuances regarding this empirical support, see Watkins (2021b).
} 
inheritance. Third, the parity thesis implies that genetic factors should not be privileged in explanations of development; the controls of developmental processes are distributed among many resources. This is what has resulted in DST being described as "a kind of extreme anti-preformationism" (GodfreySmith, 2000, 2001). A fourth consequence of the parity thesis and of focusing on developmental systems as a whole is that the organism and the environment co-cause one another: both organism and environment are involved in the same developmental system, each part of which can be causally efficacious. Co-causation between organism and environment has, in turn, caused developmental systems theorists to pay special attention to niche construction (how an organism's behavior shapes its own environment and thereby its own selective pressures). Niche construction also relates directly to DST's expanded view of inheritance; organisms inherit the niche which was, in part, constructed by past generations.

Proponents (and some opponents) of DST have also clarified the implications of DST for a number of related topics, including modularity (Moss, 2001; Griffiths and Gray, 2001), innateness (Griffiths, 2002), information theory (Griffiths and Gray, 2004; Griffiths, 2017), the difference between interand intraindividual comparisons (Molenaar et al., 2003), and process ontology (Griffiths and Stotz, 2018). There has also been extensive discussion over the methodological implications of DST, including whether there are any (Ford and Lerner, 1992; Wimsatt, 2001; Godfrey-Smith, 2001; Molenaar et al., 2013; Longino, 2013). Relatedly, there has been some debate about whether DST is "experimentally unwieldy" (Robert et al., 2001) due to advancing an extreme holism or whether it has empirical consequences (Sterelny and Kitcher, 1988; Sterelny et al., 1996; Griffiths and Gray, 1997; Oyama, 2000; Griffiths and Gray, 2005; Griffiths and Hochman, 2015).

Despite the efforts of DST proponents, mainstream biology still tends to treat genes and environmental factors as acting in combination to produce phenotypes. This standard "interactionist" view is antithetical to the claims of DST proponents, as it continues to treat genes and environments as two distinct causes. The more radical claim that all developmental resources should be treated on a par has overwhelmingly not been adopted. That said, there are some notable exceptions, many of which are, I believe, often overlooked by explicit advocates of DST. In order to highlight the similarities between DST and some other work in theoretical developmental biology, I will also elaborate on several other views which seek to incorporate developmental biology more thoroughly into theoretical and evolutionary biology. DST proponents and those who propound these other views have in common that they are seeking a "developmental update" to theoretical biology.

I will focus especially on the arguments given by West-Eberhard (2003), who provides undoubtedly the most extensive treatment of the theoretical implications of developmental biology, although I will cite others who have made similar arguments when appropriate. Like the proponents of DST, WestEberhard notes that, historically, the role of genes in development and evolution has been privileged over the role of any other factor, including envi- 
ronmental ones (p. 4). She attributes this to neglect of developmental biology by evolutionary biology, ${ }^{6}$ which has focused more on advances within molecular biology (p. 6, 17, 19, 193, 335; although see Gilbert 2017 regarding the reemergence of developmental biology at the fore of biological research). WestEberhard, like other developmental update proponents, criticizes the use of metaphors for the role of genes, such as the "program" metaphor and the "blueprint" metaphor (p. 13-15; see also Nijhout 1990; Pigliucci 2001, p. 21, $50,68,115,129)$. She emphasizes the ubiquity of developmental plasticity, or the ability of an organism to change its phenotype in response to different environmental conditions (p. 33); West-Eberhard calls this feature of development "condition sensitivity" (e.g., p. 17; see also Pigliucci 1998, 2001; Gilbert 2005). This lines up with DST's emphasis on the contingency and contextual dependence of development.

West-Eberhard also argues at length for the interchangeability of genetic and environmental factors in producing phenotypes; while she stops short of claiming that there is no causal distinction between the two, she does think that any given developmental process can be triggered by genetic or environmental switches (p. 19, 99), and that genetic and environmental factors can similarly become entrenched in the developmental process (p. 500-503). For instance, she claims that both genes and the environment can serve exactly two roles in development: as information, or as building blocks (p. 107-108). West-Eberhard thus takes herself to be claiming that genetic and environmental factors interact in development, not just in the trivial sense that no phenotype is produced without some genetic and some environmental influence (a view that traditionally takes genes to be serving the informational role, while the environment just provides building blocks), but in the stronger sense that development is influenced by genes and the environment in identical ways. West-Eberhard would, then, likely agree with DST proponents on the interactive nature of development. She also indicates a similar rejection of (or solution to) the nature-nurture debate (p. 3, 33, 329, 499; see also Pigliucci 2001, p. 124, 254).

West-Eberhard (2003)'s aim is to provide a revised understanding of evolution in light of these developmental principles, and can thus be compared with Griffiths and Gray (1994). West-Eberhard and Griffiths and Gray do not agree on everything when it comes to the relationship between developmental and evolutionary biology (and their disagreements will be discussed to some extent in section 4), but several of their claims are compatible. West-Eberhard emphasizes that selection acts on phenotypes, which are the result of developmental processes influenced by both genetic and environmental factors (p. 16). As West-Eberhard notes, then, "The environmental sensitivity of development means that environmental variation can be a source of the selectable phenotypic variation that fuels adaptive evolution" (p. 29; see also Gilbert et al. 2015;

\footnotetext{
6 Including evolutionary developmental biology ("evo-devo"), which "extensively treats the genomic correlates of gross morphological variation across phyla, with little or no discussion of behavior, physiology, life histories, and the kind of variation within populations that is required for natural selection to work" (p. 89).
} 
Moczek et al. 2011). Environmentally induced phenotypes can serve the same role evolutionarily as genetically induced phenotypes, including recurrence and heritability (p. 144). Selected-for traits will have an increased frequency of expression, which, as a consequence of gene-environment interchangeability, can be either genetically or environmentally caused (p. 149). West-Eberhard does want to reserve the gene-environment distinction (e.g., she thinks that adaptive evolution always involves gene frequency changes), thereby disagreeing with the metaphysical claims of DST proponents. However, she views evolutionary change in much the same way as advocates of DST: a whole host of developmental resources can be inherited, are required for development, and will produce phenotypes upon which selection acts.

Another viewpoint which is unofficially allied with that of DST is a view held by some of the proponents of the so-called Extended Evolutionary Synthesis (EES). The Extended Evolutionary Synthesis, as the name suggests, is supposed to extend the Modern Synthesis (MS) between Darwinian natural selection and Mendelian genetics, in particular to include new theoretical results from developmental biology. A brief examination of some of the claims of EES proponents will make apparent the similarities with DST and other developmental update proponents. Laland et al. (2015) give a brief overview of the main differences between the MS and the EES. They list the following principles of the EES: (1) reciprocal causation, (2) inclusive inheritance, (3) nonrandom phenotypic variation, (4) variable rates of change, (5) an organismcentered (rather than gene-centered) perspective, and (6) developmental bias in macroevolution (p. 2). Several of these principles match up with the tenets of DST, and thus also with claims made by West-Eberhard inter alia. For instance, both DST and EES proponents are unsatisfied by an overemphasis on genetic, rather than epigenetic or environmental, causes of phenotypes. Reciprocal causation between organisms and their environment, as well as an extended view of inheritance, is emphasized explicitly by DST proponents. Non-random variation and developmental bias in macroevolution are not a focus of DST, but both of these principles are consistent with many of the claims of DST, especially insofar as both emphasize the importance of development and developmental systems. Centering the organism in the EES is related to the debate over units of selection; I will discuss this (as well as the issue of rates) in section 4 . For further discussion on the merits of an ESS, see Laland et al. (2014) as well as Pigliucci and Schlichting (1997) and Pigliucci (2006, 2007).

Importantly, the developmental update position should be distinguished from various other positions which are informed by developmental biology but which, unlike the developmental update view, do not call for broad revision of biological theorizing. For instance, many developmental biologists have no problem with the central dogma of molecular biology; these biologists should not be considered to be proponents of what I've been calling a devel- 
opmental update, regardless of their other views. ${ }^{7}$ Other scholars have also discussed the difference between DST and evolutionary developmental biology, also known as "evo devo" (Robert et al., 2001; Jablonka and Lamb, 2002; Griffiths and Gray, 2004). ${ }^{8}$ For instance, Robert et al. (2001) notes that DST proponents (among other developmental update proponents I have discussed here) emphasize the inheritance of not just genes and epigenetic potential, but also epigenetic processes and environmental factors, whereas evo-devo as a research program tends to only emphasize genetic inheritance and inheritance of epigenetic potential (p. 960). While it is outside of the scope of this paper to further discuss other, developmentally-informed positions which do not call for a developmental update, it is important to note that there are such positions.

The goal of this section was to provide an overview of the positions which involve advocating for a developmental update to theoretical biology. However, the main focus of this paper is on four specific themes of the developmental update: units of selection, modes of inheritance, reciprocal causation, and rates of evolution.

\section{The Developmental Update and Microbiology}

This section zooms in on these four themes and discusses the developmental update arguments concerning them, as well as how these arguments have tended to neglect relevant microbiological evidence. I have chosen these four themes because I think in each case a focus on microbiological research, and not just developmental biological research, has the potential to motivate the same sorts of updates to biological theory. I will thus be using these four themes to argue that a focus on developmental biology as the evidence base for these theoretical consequences is not better in principle than a focus on microbiology, and thus that the focus on developmental biology is most likely a historical accident. To be clear, I don't intend to pit developmental biologists against microbiologists in any way, nor to fault developmental biologists for their lack of focus on microbiological results. However, I do think that it is an interesting historical fact that developmental update proponents have solely used developmental evidence and not microbiological evidence to make their points.

\subsection{Units of Selection}

A focus on entire developmental systems, rather than just their component parts, complicates the units of selection debate. For starters, developmental update proponents are, predictably, going to reject any claim that genes are the appropriate units of selection, as well as any replicator-vehicle distinction upon

\footnotetext{
7 Regarding the overlapping research programs of developmental and molecular biology, see Love (2020).

8 For philosophical work on evo-devo, see, e.g., Love (2015, 2017).
} 
which that claim rests (Gray, 1992). So far, though, there is not agreement among developmental update proponents about what the appropriate units of selection should be, exactly, although there does seem to be agreement that developmental biology bears on the units of selection debate.

One proposal offered by DST theorists is that the appropriate unit of selection is the life cycle (Griffiths and Gray, 1994). Griffiths and Gray think that, while entire developmental systems are replicated from one generation to the next, the emphasis of evolutionary theorists should not include the merely persistent features of these systems (e.g., gravity, sunlight), despite the importance of these features to development (p. 290; although, note that, confusingly, Griffiths and Gray 2001 say, "Fundamentally, the unit of both development and evolution is the developmental system, the entire matrix of interactants involved in a life cycle," p. 206). Instead, Griffiths and Gray argue that a DST approach would focus on the replication of developmental processes, where a developmental process is "a series of events which initiates new cycles of itself" (p. 291). Each repetition of that developmental process - each life cycle - is an evolutionary individual (p. 293). Griffiths and Gray grant that these cycles can apply to different levels of analysis, e.g., cellular or organismal (p. 295).

Pradeu (2010) argues against this view of units of selection, suggesting that the organism should still be considered the appropriate biological individual, insofar as the relevant explanandum of DST is the characteristics of the organism (p. 217). Keller (2001) also argues for an emphasis on the organism; she thinks that omission of the significance of the body itself (in some cases, she specifically refers to the cell) is too closely "reminiscent of conventional maternal discourse" which treats the woman's body (or, the cytoplasm of her egg cell) as merely a source of nurture for a developing embryo.

West-Eberhard (2003) also disagrees with Griffiths and Gray (1994), although her disagreement stems from the continuity of the phenotype, or "the unbroken and overlapping connections between generations mediated by parentally constructed offspring phenotypes" (p. 93). The lines between life cycles are blurred by the continuity of the phenotype, and are connected via what WestEberhard calls an "inherited bridging phenotype - a responsive, organized cell provided by a parent in the form of an egg, a newly divided cell, or a set of cells that springs entirely from the previous generation, is adapted for survival and interaction in the gametic and embryonic environment, and is the active and organized field upon which the zygotic/offspring genome products and subsequent environments eventually act" (p. 91). In other words, WestEberhard thinks that the gamete itself (for example) has a set of phenotypes, which are inherited by the zygote. This gametic phenotype is pre-adapted to the developmental environment, due to its own history of gene-environment interaction, such that the development of the organism cannot be said to start with fertilization (or anywhere else, for that matter). Similar to Keller (2001), then, West-Eberhard argues that focusing on the life cycle misrepresents the importance of the material inheritance of gametic cell matter. West-Eberhard thus advocates for a "phenotype-centered" view of evolution, wherein selection 
acts on phenotypes (p. 31, 98; note that Griffiths and Gray 2001, p. 198 seem to agree with this).

Griffiths and Gray (1997), in responding to some criticisms provided by Sterelny et al. (1996), attempt to address this problem of how to divide life cycles precisely (see Griffiths and Gray 2001, 2004 for further elaboration on these points). Reiterating their arguments in Griffiths and Gray (1994), they say that DST defines a life cycle by the recurrence of processes; the regularity of different developmental stages allows one to divide up a lineage into different generations (p. 477). While this may respond to Sterelny et al.'s concerns, it does not specifically address the continuity of the phenotype nor the importance of inherited cellular resources.

Sterelny et al. (1996), and Griffiths and Gray (1997) in response, also identify another problem with life cycles: that it is hard to distinguish different life cycles or even different lineages in cases of tight-knit coevolution (p. 478). In response, in one of the rare instances where DST proponents refer to results from microbiology, Griffiths and Gray cite Margulis (1970, 1981) for the claim that "the eukaryotic cell descends from a symbiotic association of previously free-living organisms" (p. 478). Griffiths and Gray also refer to cases of obligate symbiosis between microorganisms and their hosts, as well as slime molds and lichens, as cases that complicate the distinction between discrete life cycles ( $\mathrm{p}$. 478-479). Other discussions of the units of selection in the context of DST are also liable to mention microbial symbioses (e.g., Sterelny 2001, p. 342, 345; Griffiths and Gray 2001, p. 198, 200, 210; Griffiths and Gray 2004, p. 410, 412). Somewhat surprisingly, there is no mention of holobionts in the DST literature, that I know of.

There is nothing in developmental biology that settles the debate between these different options for the units of selection; some developmental update proponents have cogently argued for focusing on the life cycle or the organism, but it is also compatible with their view to focus on phenotypes or holobionts. The main disagreement that developmental update proponents have with nondevelopmental update proponents is that the units of selection are unlikely to be nicely nested levels of selection - from genes to species - but rather have to accommodate the important interactions between different levels and between different developmental resources which occur throughout a developmental system. This proposed revision to our units of selection concept is supposed to be tied to developmental biology in particular insofar as a focus on developmental systems - a developing organism and its developmental resources provides the impetus for this revision.

To reiterate, the point here is not that developmental update proponents require an examination of microbiological evidence in order to levy their general criticism of the standard view of units of selection: their criticism stands merely on the basis of the developmental biological research which they highlight. Instead, I think that an identical criticism pertaining to units of selection can be levied from the perspective of microbiology, as we saw in section 2.1. Thus, the results in developmental biology are sufficient but not necessary to motivate an adjustment of our units of selection; the critique of the received 
view is more widespread than a focus on developmental biology would indicate. The exact details of what our units of selection should be adjusted to still needs to be fleshed out; a combination of developmental and microbiological evidence may be necessary for this project.

\subsection{Modes of Inheritance}

As discussed above, proponents of a developmental update advocate for an expanded view of inheritance, one which encompasses the variety of developmental resources organisms inherit other than the genes they receive from their parents. For example, organisms inherit environments (more on this in section 4.3 ), behaviors, preferences, and more. An expanded view of inheritance is supposed to be tied to results in developmental biology insofar as a focus on all developmental resources (as opposed to merely genetic resources) has enabled recognition of the fact that any of these resources might be inherited, and may affect evolutionary trajectories accordingly. ${ }^{9}$

Modes of inheritance, unlike units of selection, is a topic on which nearly all developmental update proponents agree (for a possible exception, see Pradeu 2010). I will first go through the main inheritance-related claims of DST, in roughly chronological order. Gray (1992) argues for an "expanded view of inheritance" which includes cytoplastmic factors, chemical traces, gut microorganisms, social traditions, and features of the environment (p. 179-181; see also Oyama et al. 2001, p. 3-4; Stotz 2008, p. 371). Griffiths and Gray (1994) grant that inheritance may be horizontal (between members of one generation) rather than just vertical (from parent to offspring), for instance, in the case of language inheritance as well as LGT (p. 303). Griffiths and Gray (1997) discuss the epigenetic inheritance system, which involves inheriting cellular resources necessary for DNA activation and replication (p. 473; see also Jablonka and Lamb 1995, chpt. 4; Griffiths and Knight 1998, p. 254; Griffiths and Tabery 2013, p. 80; Griffiths and Hochman 2015, p. 4), and contrast their view with the gene-centric extended replicator theory of Sterelny et al. (1996). Griffiths and Gray (2001) go on to discuss further ways in which DST's theory of inheritance differs from the standard, gene-only and vertical-only theory of inheritance, including vertical or horizontal inheritance of extracellular resources such as the environment or other sources of information (cf. Sterelny 2001). Jablonka and Lamb (2002) distinguish DST from evo-devo by the latter's insistence that genes are the sole units of heredity (p. 290; see also Griffiths and Gray 2004, p. 410, although cf. Griffiths and Gray 2005, p. 422). Jablonka and Lamb (2005) say that there are four categories of inheritance - genetic, epigenetic, behavioral, and symbolic - all of which are interrelated and can have evolutionary importance (see also Jablonka 2001). Jablonka and Lamb (2005), among others, also recognize that an expanded view of inheritance is likely to sound like the Lamarckian inheritance of acquired characteristics (e.g., Stotz 2010,

9 For a discussion of the relationship between developmental biology and expanded views of inheritance, see Jablonka (2007). 
p. 490); some reject this interpretation, but developmental update proponents largely embrace it (see Jablonka and Lamb 2005, p. 13 for an argument). All of these authors agree that non-genetic inheritance can and likely does affect evolution (for an explicit argument to this effect, see Griffiths 2017, p. 6).

Other developmental update proponents agree that non-genetic resources can be inherited (e.g., West-Eberhard 2003, p. 115). In particular, Gilbert et al. (2012), Gilbert (2014), and Gilbert and Epel (2015) emphasize the likely importance of inherited microbial endosymbionts. Microbes as an inherited developmental resource are also relatively well-recognized by DST proponents (e.g., Gray 1992; Griffiths and Gray 2001; Griffiths 2002). However, as I argued in section 2.2 , it is not only in their roles as symbionts that microorganisms challenge the received view of inheritance; other mechanisms such as LGT indicate that an update to biological theory is in order. Developmental update proponents also usually ignore directed mutagenesis as a possible instance of this phenomenon. A unique exception is given by Jablonka and Lamb (1995, 2005), who do discuss directed mutations, including in both the microbial and non-microbial contexts (e.g., Jablonka and Lamb 2005, chpt. 3).

Thus, again, the developmental biological evidence is sufficient but not necessary to recommend an update concerning modes of inheritance, and much microbiological evidence to this effect has been ignored by developmental update proponents. Microbiological evidence pertaining to modes of inheritance includes the importance of horizontal inheritance (especially via LGT and endosymbiosis), but also directed mutagenesis and epigenetic inheritance. Each of these issues are important to the developmental update as well.

\subsection{Reciprocal Causation}

The insights of developmental update proponents begin with the claim, accepted by all, that the environment is a necessary causal factor in development. This empirical fact has led some developmental update proponents, especially DST theorists, to focus on developmental systems, which include the organism and all of the resources influencing its developmental trajectory. Developmental update proponents have noticed, though, that it is not just the case that the environment (among other developmental resources) affects the developmental process, but that the organism and its development can affect the environment as well.

The most extensively theorized way in which an organism can affect its environment is through niche construction (Odling-Smee et al., 1996, 2003; Laland et al., 2001). Niche construction occurs when organisms influence their environments in ways that change the selective pressures on the organism, which, in turn, can have an impact on the evolutionary success of that organism's descendants. As Odling-Smee et al. (2003) point out, niche construction is thus not merely a consequence of evolution but part of the process of evolution itself, especially insofar as the resulting constructed niches are inherited just as any other developmental resource (p. 116; see also Odling-Smee et al. 
1996, although cf. Sterelny 2001). Responsiveness of the organism to the environment plays a crucial role in niche construction: organisms must be able to respond to the environment they are currently in in the right kind of way for niche construction to occur successfully (Gilbert et al., 2015).

Many proponents of a developmental update have discussed niche construction, due to the "underlying idea that organisms actively construct their environments and by this means provide another inheritance mechanism" (Stotz 2010, p. 485; see also Stotz 2008). Insofar as a developmental update involves the observation that entire developmental systems are reproduced and reconstructed each generation, the environmental components of a developmental system must also be thus reproduced, a process which occurs in part due to the actions of the organisms themselves (Griffiths and Tabery, 2013, p. 81). However, as Griffiths and Gray (2001) point out, "niche construction is still a fundamentally dichotomous account of evolution" because there are, on the one hand, selective pressures coming from the environmental niche acting on the organism and, on the other hand, construction of the environmental niche by the organism (p. 206; see also Gray 1992). Developmental update proponents prefer to do away with these dichotomies, and instead think about the coevolution of organisms and environment or, more specifically, the reciprocal causation among all parts of a developmental system (Griffiths and Gray, 1994; Griffiths and Knight, 1998; Oyama et al., 2001; Griffiths and Gray, 2004). Furthermore, as Lewontin (2001) points out, not only can organisms influence their environment by consuming or creating resources, potentially making the environment more or less hospitable to their progeny, but organisms also define and interpret their environments based on how the environment is related to their development (p. 64). In other words, what counts as a relevant feature of the environment is in large part determined by the organism, so even if the organism is not physically altering its environment in any way, the organism is still somewhat selecting which surrounding resources constitute its environment.

In the context of reciprocal causation, or even in the more specific context of niche construction, I have found only one case where developmental update proponents have discussed microorganisms as agents of environmental change: Jablonka and Lamb (2005) say, "Even bacteria and blue-green algae (Cyanobacteria), the oldest inhabitants of our planet, can be thought of as ecological engineers" (p. 237). With this one exception, developmental update proponents appear to only focus on the role of microorganisms in these cycles when the microorganisms are serving as symbionts, i.e., as developmental resources. For example, rhizobia, the nitrogen-fixing bacteria which has formed facultative or obligate symbioses with many plants, is a classic example of symbiosis used by developmental biologists (e.g., Gilbert and Epel 2015). However, this would be theorized along with other symbioses, not as an instance where the rhizobia are undertaking niche construction. Taking a microbe-centered view of the rhizobia case would lead to a richer analysis, and one compatible with the theoretical goals of the developmental update. 
Take also the case of Wolbachia, the aforementioned insect parasite. Griffiths and Gray (2001), for example, recognize Wolbachia as a developmental resource (i.e., something which affects development) that can be inherited (p. 200), as does West-Eberhard (2003, p. 528). The niche construction framing of the Wolbachia case, on the other hand, wouldn't treat Wolbachia as a developmental resource, but as a developmental system in its own right, capable of shaping and being shaped by its environment (of which the hosts are a part). This framing of the case has thus far been overlooked by developmental update proponents.

As was the case with units of selection and modes of inheritance, then, while developmental update proponents have perhaps adequately made their case regarding reciprocal causation solely on the basis of developmental biological evidence, an identical case can be made by using an examination of microbiological evidence. Developmental results are not necessary to make the claims that developmental update proponents want to advance regarding reciprocal causation.

\subsection{Rates of Evolutionary Change}

This final section is about an underemphasized implication of developmental biology, especially within DST: that a developmental systems view may affect what we think about the rates of evolution. ${ }^{10}$ Changing the expected rates of evolution is a direct consequence of focusing on multiple, potentially nongenetic, modes of inheritance. Horizontal inheritance in particular has clear implications for rates: if fully functional traits can be passed on horizontally, rather than vertically, evolutionary change can be seen in a minimum of zero generations. Change by means of vertical inheritance (i.e., by random genetic mutation) requires a minimum of one generation.

Despite this relatively straightforward inference, proponents of a developmental update have by and large neglected to focus on rates of change. Indeed, I have found only very rarely any discussion of rates in the developmental update-friendly literature. For example, Jablonka and Lamb (2005) discuss the implications of epigenetic inheritance for rates of change explicitly: "adaptation through the selection of epigenetic variants may be quite rapid compared with adaptation through genetic change" (p. 145; see also Jablonka and Lamb 1995). Jablonka and Lamb also indicate that rapid speciation events may be caused by epigenetic or even behavioral changes, rather than genetic ones (p. 144-145, 184, 250, 309). Horizontal inheritance in particular (which may be genetic, but can also be epigenetic or behavioral) can cause the rates

\footnotetext{
10 There is some interesting new work on integrating developmental biology and paleontology in discussions surrounding rates (e.g., Jablonski 2020; Jackson 2020). For example, developmental biologists may be able to study "evolvability," which then can affect paleontologists' prediction of rates. Nevertheless, these issues largely have not been picked up by developmental update proponents as such. For further discussion of the relationship between developmental biology and paleontology, see Watkins (2021a).
} 
of change to be higher than they would be with only vertical inheritance (p. 188).

Actually, West-Eberhard notes that developmental plasticity can affect rates of change either by increasing them or decreasing them (p. 178; see also Pigliucci 2001, p. 57-58, 213 for a very brief mention of this), including by potentially causing speciation events (2003, chapter 27). Plasticity can increase rates of evolution in the manner similar to the one mentioned above: if all members of a given population are exposed to novel environmental conditions, and react phenotypically to those conditions in the same, novel way, then the members of that population will express a novel (potentially adaptive!) phenotype all at once; this, in contrast to the usual story that involves only a few "lucky" individuals with appropriate genetic mutations expressing the phenotype which matches the novel environment. Plasticity can also, though, decrease rates of change in cases of hyperplasticity, such as learning, because in such cases it is extremely unlikely that plasticity will produce any recurring phenotype at all. West-Eberhard is unique among developmental update proponents in noting these possible implications of plasticity for the rates of change. Thus, evidence of the effect of developmental plasticity on evolution has inspired some developmental update proponents to call for a reevaluation of rates.

One reason why developmental update proponents may avoid talking about rates of change is their constant effort to distance themselves from anything remotely resembling Larmarckism or saltationism. Even West-Eberhard, despite her recognition of the relationship between developmental plasticity and rates of change, goes to great lengths to demonstrate that she does not think that acquired characteristics can be inherited, in order to show that her remarks about evolution are perfectly consistent with the neo-Darwinian account (e.g., West-Eberhard 2003, chpt. 24). At least some theorists using microbiology as their starting place have not tended to shy away from Larmarckism to quite the same degree (e.g., Koonin and Wolf 2009). Accordingly, and in line with Jablonka and Lamb (1995, 2005), I am more inclined to think that developmental update proponents and others who advocate for a re-centering of developmental biology in evolutionary theorizing should treat inheritance of acquired characteristics and saltation as legitimate, empirically-testable hypotheses, thereby re-framing these historical debates using new evidence and methods. The field of microbiology has been able to sanction a reexamination of rates of change on the basis of horizontal inheritance, without continuing to view all proposed instances of immediate change as heretical.

Therefore, again, the evidence base that developmental update proponents could use to advocate for a revision to the presumed rates of evolutionary change could include microbiological evidence. If developmental update proponents were to begin to advocate more seriously for a reevaluation of rates, the microbiological evidence would serve them well. 


\section{Summary and Discussion}

I have argued that at least four themes of the proposed developmental update - regarding units of selection, modes of inheritance, reciprocal causation, and rates of change - can also be seen as consequences of microbiological research. In particular, I have focused on results in microbiology about microorganisms themselves, rather than on results which treat microorganisms only as developmental resources in a developmental system centered on a larger, multicellular organism, like an animal or a plant.

In the case of units of selection, developmental update proponents have noticed that focusing on the developmental system as a whole complicates how we should think about biological individuality. There is not currently agreement among developmental update proponents or DST-friendly biologists over what the units of selection should be, exactly, but I have argued that a focus on microbial communities such as biofilms complications the units of selection debate in exactly the same way as a focus on developmental systems does. In the case of modes of inheritance, by contrast, there is widespread agreement among developmental update proponents that inheritance should be expanded to include horizontal inheritance as well as vertical inheritance, and that nongenetic resources can be inherited in much the same way as genetic resources can. I have argued that both of these conclusions also follow from focusing on microbial inheritance mechanisms, including LGT, directed mutagenesis, and epigenetics. In the case of reciprocal causation, developmental update proponents have argued that organisms should be seen as agents of environmental change (including niche construction); I have argued that microorganisms also affect their environment in this way. Finally, in the case of rates of evolution, I have argued both that developmental update proponents should more fully recognize the implications of their view - that rates of evolution may increase or decrease depending on the sort of environmental contingencies involved and that these implications can be seen through a microbiological lens as well. In all cases, developmental biological evidence is sufficient but not necessary for reaching the theoretical conclusions - microbiological evidence suffices as well.

Why hasn't the microbiological evidence cited above had the same degree of influence on biological theory as the developmental biological evidence? Why might developmental update proponents have focused on developmental biology rather than microbiology? One related question, posted by Griffiths and Gray (2004): "What, one might ask, is developmental about developmental systems theory?" (p. 425). On the one hand, it is easy to see that microorganisms (at least, single-celled microorganisms) aren't going to be particularly relevant to developmental biology, if development requires cell differentiation. However, the explanation that I prefer is that it is just a historical accident that developmental systems theorists along with other developmental update proponents focused on developmental biology and not microbiology. Griffiths and Stotz (2018) explain: "most scientific work in the developmental systems tradition was on behavior development, ... [and] philosophical discussion of 
DST focused on its implications for 'gene-centered' views of molecular developmental biology and evolutionary biology" (p. 225-226). This trend seems to me to be more a consequence of the prior interests and expertise of these biologists and philosophers than of any principled reason to focus on developmental biology per se. Thus, I would posit that there nothing (or, at least, very little) especially developmental about DST or about the developmental update.

There are other historically contingent reasons that might explain why developmental update proponents have focused solely on developmental biology, rather than on both developmental and microbiology. I will gesture at a few of these. First of all, I think that it is possible that the close relationship between microbiology and molecular biology turned developmental update proponents off to microbiology, because part of their position is to limit the focus on molecular biology. However, I hope to have shown in section 2 that the contributions of microbiology exceed those related to molecular biology. Second, historically it has been true that much research in microbiology has focused on disease, rather than on evolution. ${ }^{11}$ Studying microbes as more than possible sources of infection, and outside of medical schools, is a relatively recent development, a fact which may have contributed to the sidelining of microbiology by developmental update proponents.

Looking to the future, it is actually not necessarily the case that a developmental perspective cannot include a microbiological perspective. Indeed, it is rather odd to compare and contrast microbiology - which encompasses two entire domains of life - with developmental biology; microbiology is perhaps more aptly compared to a combination of botany, mycology, and zoology, the main areas of study for macrobial life. ${ }^{12}$ The assumption that microorganisms do not develop is common, although most likely false, depending on how we conceive of development. O'Malley (2014) mentions the field of microbial developmental biology, which has broadened the definition of development to include not just cell differentiation within one organism but also cell differentiation in response to environmental conditions (p. 119). For example, Myxососcus bacteria form social groups, and cells in different parts of these groups adopt different phenotypes (O'Malley 2014 lists several other examples as well; see pages 119-120). Developmental update proponents would likely be very sympathetic to this broadened conception of development, but it has gone unmentioned in the developmental update-related literature thus far, perhaps because many developmental update proponents think that microbes do not exhibit developmental properties. O'Malley (2014) also discusses an even broader conception of development, one which would allow that unicellular organisms can themselves develop. Specifically, the ability for single cells to take on different phenotypes in response to environmental conditions resembles the process of development insofar as it is a product of both genetic and environmental information and resources. These considerations have led

11 Thanks to an anonymous reviewer for pointing out this possible explanation.

12 Thanks to an anonymous reviewer for suggesting this. 
Love and Travisano (2013), for example, to argue that microbes can serve as model organisms in the context of developmental biology. Accordingly, I think that a further examination of the definition of development, and in particular whether it could apply to single-celled microorganisms, would be a fruitful area of future research for developmental update proponents to pursue.

One final remark concerns the fact that developmental biology and microbiology happen to have many of the same theoretical consequences. Of course, one could view this as purely coincidental, or as the result of the fact that the empirical results in microbiology and developmental biology aren't as easily separable as I have made them out to be. Another possibility, though, is that we have a convergence of multiple lines of evidence in favor of the same theoretical postulates. Convergence is often taken as additional confirmation. So, perhaps the fact that developmental and microbiologists agree with respect to a few theoretical claims should count as an argument in favor of these claims.

\section{Conclusion}

I have argued that microbiological evidence, as well as evidence from developmental biology, supports at least four of the revisions to biological theory argued for by developmental update proponents, concerning: units of selection, modes of inheritance, reciprocal causation, and rates of evolution. In all of these cases, both developmental and microbiological evidence is sufficient to recommend a theoretical update. This raises the question of why developmental update proponents have neglected microbiological evidence, or why microbiological evidence hasn't independently been taken to recommend a large-scale update to biological theory. I have argued that there is no inprinciple reason that developmental as opposed to microbiological evidence has been used to this end, and suggested that it is more likely the result of historical contingencies. Additionally, I have suggested that the scope of "development" be broadened to make a combination of microbiological and developmental evidence more commonplace.

The purpose of this paper has been to show that there are major areas about which developmental and microbiological evidence largely agree. However, this does not mean that they will agree in all cases. There may be some areas for which microbiological evidence recommends a theoretical update and developmental biological evidence remains silent. While this issue is outside of the scope of the present paper to address, I do think that further comparisons between the theoretical implications of developmental and microbiological evidence - including on areas where they disagree - is a fruitful line of research.

Acknowledgements This paper greatly benefited from feedback by Rachell Powell, Maureen O'Malley, and Alan Love, as well as comments from two anonymous reviewers and Associate Editor Emily Parke. This material is based upon work supported by the National Science Foundation Graduate Research Fellowship Program under Grant No. DGE-1840990. Any opinions, findings, and conclusions or recommendations expressed in this material are 
those of the author and do not necessarily reflect the views of the National Science Foundation.

\section{Conflict of interest}

The author declares that they have no conflict of interest.

\section{References}

Bateson P (1978) Sexual imprinting and optimal outbreeding. Nature 273(5664):659-660, DOI 10.1038/273659a0

Bateson P (1983) Genes, Environment and the Development of Behaviour. In: Slater P, Halliday T (eds) Animal behaviour: Genes, development, and learning, Blackwell

Bateson P (2001) Behavioral development and darwinian evolution. In: Oyama S, Griffiths PE, Gray RD (eds) Cycles of contingency: developmental systems and evolution, MIT, Cambridge, Mass.; London, pp 149-166

Bi J, Wang YF (2020) The effect of the endosymbiont Wolbachia on the behavior of insect hosts. Insect Science 27(5):846-858, DOI https://doi.org/10.1111/1744-7917.12731, URL https://onlinelibrary.wiley.com/doi/abs/10.1111/1744-7917.12731, _eprint: https://onlinelibrary.wiley.com/doi/pdf/10.1111/1744-7917.12731

Bitton G (2005) Role of Microorganisms in Biogeochemical Cycles. In: Wastewater Microbiology, John Wiley \& Sons, Ltd, pp 75-105

Canfield D (2005) The early history of atmospheric oxygen: Homage to Robert M. Garrels. Annual Review of Earth and Planetary Sciences 33(1):1-36, DOI 10.1146/annurev.earth.33.092203.122711

Carmichael L (1925) Heredity and environment: are they antithetical? The Journal of Abnormal and Social Psychology 20(3):245-260, DOI $10.1037 / \mathrm{h} 0074125$

Cox CJ, Foster PG, Hirt RP, Harris SR, Embley TM (2008) The archaebacterial origin of eukaryotes. Proceedings of the National Academy of Sciences of the United States of America 105(51):20356-20361, DOI 10.1073/pnas.0810647105, URL https://www.ncbi.nlm.nih.gov/pmc/articles/PMC2629343/

Crick FH (1958) On protein synthesis. Symposia of the Society for Experimental Biology 12:138-163

Dawkins R (1976) The selfish gene: 40th anniversary edition. Oxford University Press, New York, NY

Doolittle WF, Booth A (2017) It's the song, not the singer: an exploration of holobiosis and evolutionary theory. Biology \& Philosophy 32(1):5-24, DOI $10.1007 / \mathrm{s} 10539-016-9542-2$

Ford DH, Lerner RM (1992) Developmental systems theory: an integrative approach. Sage Publications, Newbury Park, CA 
Gilbert SF (2005) Mechanisms for the environmental regulation of gene expression: Ecological aspects of animal development. Journal of Biosciences 30(1):65-74, DOI 10.1007/BF02705151

Gilbert SF (2014) A holobiont birth narrative: the epigenetic transmission of the human microbiome. Frontiers in Genetics 5, DOI 10.3389 /fgene.2014.00282

Gilbert SF (2017) Developmental biology, the stem cell of biological disciplines. PLOS Biology 15(12):e2003691, DOI 10.1371/journal.pbio.2003691, publisher: Public Library of Science

Gilbert SF, Epel D (2015) Ecological developmental biology: the environmental regulation of development, health, and evolution, second edition edn. Sinauer Associates, Inc. Publishers, Sunderland, Massachusetts, U.S.A

Gilbert SF, Sapp J, Tauber AI (2012) A Symbiotic View of Life: We Have Never Been Individuals. The Quarterly Review of Biology 87(4):325-341, DOI 10.1086/668166, URL https://www.journals.uchicago.edu/doi/full/10.1086/668166, publisher: The University of Chicago Press

Gilbert SF, Bosch TCG, Ledón-Rettig C (2015) Eco-Evo-Devo: developmental symbiosis and developmental plasticity as evolutionary agents. Nature Reviews Genetics 16(10):611-622, DOI 10.1038/nrg3982, number: 10 Publisher: Nature Publishing Group

Godfrey-Smith P (2000) Explanatory Symmetries, Preformation, and Developmental Systems Theory. Philosophy of Science 67:S322-S331

Godfrey-Smith P (2001) On the status and explanatory structure of developmental systems theory. In: Oyama S, Griffiths PE, Gray RD (eds) Cycles of contingency: developmental systems and evolution, MIT, Cambridge, Mass.; London, pp 283-298

Gottlieb G (1970) Conceptions of prenatal behavior. In: Aronson L, Tobach E, Lehrman DS, Rosenblatt J (eds) Development and Evolution of Behavior, W.H. Freeman and Co., San Francisco, pp 111-137

Gottlieb G (1976a) Conceptions of prenatal development: Behavioral embryology. Psychological Review 83(3):215-234, DOI 10.1037/0033-295X.83.3.215

Gottlieb G (1976b) The Roles of Experience in the Development of Behavior and the Nervous System. In: Gottlieb G (ed) Studies on the Development of Behavior and the Nervous System, Neural and Behavioral Specificity, vol 3, Elsevier, pp 25-54

Gottlieb G (1981) Roles of early experience in species-specific perceptual development. In: Aslin R, Alberts J, Peterson M (eds) Development of Perception Psychobiological Perspectives: Audition, Somatic Perception, and the Chemical Senses, Elsevier

Gottlieb G (2001) A developmental psychobiological systems view: Early formulation and current status. In: Oyama S, Griffiths PE, Gray RD (eds) Cycles of contingency: developmental systems and evolution, MIT, Cambridge, Mass.; London, pp 41-54

Gray R (1992) Death of the Gene: Developmental Systems Strike Back. In: Griffiths P (ed) Trees of Life: Essays in Philosophy of Biology, Australasian 
Studies in History and Philosophy of Science, Springer Netherlands, Dordrecht, pp 165-209

Griffiths PE (2002) What Is Innateness? The Monist 85(1):70-85, DOI $10.5840 /$ monist 20028518

Griffiths PE (2017) Genetic, epigenetic and exogenetic information in development and evolution. Interface Focus 7(5):20160152, DOI $10.1098 /$ rsfs.2016.0152

Griffiths PE, Gray RD (1994) Developmental Systems and Evolutionary Explanation. Journal of Philosophy 91(6):277-304, DOI 10.2307/2940982

Griffiths PE, Gray RD (1997) Replicator II - Judgement Day. Biology and Philosophy 12(4):471-492, DOI 10.1023/A:1006551516090

Griffiths PE, Gray RD (2001) Darwinism and developmental systems. In: Oyama S, Griffiths PE, Gray RD (eds) Cycles of contingency: developmental systems and evolution, MIT, Cambridge, Mass.; London, pp 195-218

Griffiths PE, Gray RD (2004) The developmental systems perspective: organism-environment systems as units of development and evolution. In: Pigliucci M, Preston K (eds) Phenotypic Integration: Studying the Ecology and Evolution of Complex Phenotypes, Oxford University Press, pp 409-431

Griffiths PE, Gray RD (2005) Discussion: Three Ways to Misunderstand Developmental Systems Theory. Biology \& Philosophy 20(2-3):417-425, DOI 10.1007/s10539-004-0758-1

Griffiths PE, Hochman A (2015) Developmental Systems Theory. In: John Wiley \& Sons Ltd (ed) eLS, John Wiley \& Sons, Ltd, Chichester, UK, pp $1-7$

Griffiths PE, Knight RD (1998) What Is the Developmentalist Challenge? Philosophy of Science 65(2):253-258

Griffiths PE, Stotz K (2018) Developmental systems theory as a process theory. In: Nicholson DJ, Dupré J (eds) Everything flows: towards a processual philosophy of biology, Oxford University Press, Oxford, United Kingdom, pp 224-245

Griffiths PE, Tabery J (2013) Developmental Systems Theory: What does it explain, and how does it explain it? In: Advances in Child Development and Behavior, vol 44, Elsevier, pp 65-94

Guerrero R, Margulis L, Berlanga M (2013) Symbiogenesis: the holobiont as a unit of evolution. International microbiology : the official journal of the Spanish Society for Microbiology DOI 10.2436/20.1501.01.188

Gumsley AP, Chamberlain KR, Bleeker W, Söderlund U, Kock MOd, Larsson ER, Bekker A (2017) Timing and tempo of the Great Oxidation Event. Proceedings of the National Academy of Sciences 114(8):1811-1816, DOI 10.1073/pnas.1608824114, publisher: National Academy of Sciences Section: Physical Sciences

Hurst GDD, Jiggins FM, Schulenburg JHGvd, Bertrand D, West SA, Goriacheva II, Zakharov IA, Werren JH, Stouthamer R, Majerus MEN (1999) Male-killing Wolbachia in two species of insect. Proceedings of the Royal Society B: Biological Sciences 266(1420):735, DOI 10.1098/rspb.1999.0698, URL https://www.ncbi.nlm.nih.gov/pmc/articles/PMC1689827/ 
Jablonka E (2001) The systems of inheritance. In: Oyama S, Griffiths PE, Gray RD (eds) Cycles of contingency: developmental systems and evolution, MIT, Cambridge, Mass.; London, pp 99-118

Jablonka E (2007) The developmental construction of heredity. Developmental Psychobiology 49(8):808-817

Jablonka E, Lamb M (2002) Creating bridges or rifts? Developmental systems theory and evolutionary developmental biology. BioEssays 24(3):290-291, DOI 10.1002/bies.10061

Jablonka E, Lamb MJ (1995) Epigenetic inheritance and evolution: the Lamarckian dimension. Oxford University Press, Oxford ; New York

Jablonka E, Lamb MJ (2005) Evolution in Four Dimensions: Genetic, Epigenetic, Behavioral, and Symbolic Variation in the History of Life. MIT Press

Jablonski D (2020) Developmental bias, macroevolution, and the fossil record. Evolution \& Development 22(1-2):103-125, DOI https://doi.org/10.1111/ede.12313

Jackson ISC (2020) Developmental bias in the fossil record. Evolution \& Development 22(1-2):88-102, DOI 10.1111/ede.12312

Johnston TD (2001) Toward a systems view of development: An appraisal of Lehrman's critique of Lorenz. In: Oyama S, Griffiths PE, Gray RD (eds) Cycles of contingency: developmental systems and evolution, MIT, Cambridge, Mass.; London, pp 15-24

Johnston TD (2009) Developmental Systems Theory. In: Blumberg MS, Freeman JH, Robinson SR (eds) Oxford Handbook of Developmental Behavioral Neuroscience, Oxford University Press, pp 12-29

Keller EF (2001) Beyond the gene but beneath the skin. In: Oyama S, Griffiths PE, Gray RD (eds) Cycles of contingency: developmental systems and evolution, MIT, Cambridge, Mass.; London, pp 299-312

Knight J (2001) Meet the Herod bug. Nature 412(6842):12-14, DOI 10.1038/35083744, number: 6842 Publisher: Nature Publishing Group

Koonin EV, Wolf YI (2009) Is evolution Darwinian or/and Lamarckian? Biology Direct 4:42, DOI 10.1186/1745-6150-4-42

Kuo ZY (1921) Giving up Instincts in Psychology. The Journal of Philosophy 18(24):645-664, DOI 10.2307/2939656

Kuo ZY (1922) How are our Instincts Acquired? Psychological Review 29(5):344-365, DOI 10.1037/h0073689

Kuo ZY (1928) The fundamental error of the concept of purpose and the trial and error fallacy. Psychological Review 35(5):414-433, DOI $10.1037 / \mathrm{h} 0071808$

Kuo ZY (1929) The net result of the anti-heredity movement in psychology. Psychological Review 36(3):181-199, DOI 10.1037/h0075933

Kuo ZY (1967) The Dynamics of Behavior Development: An Epigenetic View. Random House

Laland KN, Odling-Smee FJ, Feldman MW (2001) Niche construction, ecological inheritance, and cycles of contingency in evolution. In: Oyama S, Griffiths PE, Gray RD (eds) Cycles of contingency: developmental systems and evolution, MIT, Cambridge, Mass.; London, pp 117-126 
Laland KN, Uller T, Feldman M, Sterelny K, Müller GB, Moczek A, Jablonka E, Odling-Smee J, Wray GA, Hoekstra HE, Futuyma DJ, Lenski RE, Mackay TFC, Schluter D, Strassmann JE (2014) Does evolutionary theory need a rethink? Nature 514(7521):161-164, DOI 10.1038/514161a

Laland KN, Uller T, Feldman MW, Sterelny K, Müller GB, Moczek A, Jablonka E, Odling-Smee J (2015) The extended evolutionary synthesis: its structure, assumptions and predictions. Proceedings of the Royal Society B: Biological Sciences 282(1813):20151019, DOI 10.1098/rspb.2015.1019

Lehrman DS (1953) A critique of Konrad Lorenz's theory of instinctive behavior. Quarterly Review of Biology 28:337-363, DOI 10.1086/399858

Lehrman DS (1970) Semantic and conceptual issues in the nature-nurture problem. In: Aronson L, Tobach E, Lehrman DS, Rosenblatt J (eds) Development and Evolution of Behavior, W.H. Freeman and Co., San Francisco

Lehrman DS (2001) A critique of Konrad Lorenz's theory of instinctive behavior. In: Oyama S, Griffiths PE, Gray RD (eds) Cycles of contingency: developmental systems and evolution, MIT, Cambridge, Mass.; London, pp $25-40$

Lerner RM (1978) Nature, Nurture, and Dynamic Interactionism. Human Development 21(1):1-20, DOI 10.1159/000271572

Levins R, Lewontin RC (1985) The Dialectical Biologist. Harvard University Press

Lewontin RC (1974) The Genetic Basis of Evolutionary Change. Columbia University Press

Lewontin RC (1982) Organism and environment. In: Plotkin H (ed) Learning, development, and culture: essays in evolutionary epistemology, John Wiley \& Sons, Ltd, pp 151-170

Lewontin RC (2001) Gene, organism, and environment: A new introduction. In: Oyama S, Griffiths PE, Gray RD (eds) Cycles of contingency: developmental systems and evolution, MIT, Cambridge, Mass.; London, pp 55-58

Lloyd E (2020) Units and Levels of Selection. In: Zalta EN (ed) The Stanford Encyclopedia of Philosophy, spring 2020 edn, Metaphysics Research Lab, Stanford University

Longino HE (2013) Studying human behavior: how scientists investigate aggression and sexuality. The University of Chicago Press, Chicago

Love A (2020) Developmental Biology. In: Zalta EN (ed) The Stanford Encyclopedia of Philosophy, spring 2020 edn, Metaphysics Research Lab, Stanford University, URL https://plato.stanford.edu/archives/spr2020/entries/biologydevelopmental/

Love AC (2007) Explaining the Ontogeny of Form: Philosophical Issues. In: Sahotra S, Plutynski A (eds) A Companion to the Philosophy of Biology, Blackwell Publishing Ltd, Oxford, UK, pp 223-247, DOI 10.1002/9780470696590.ch13, URL http://doi.wiley.com/10.1002/9780470696590.ch13

Love AC (2015) Evolutionary Developmental Biology: Philosophical Issues. In: Heams T, Huneman P, Lecointre G, Silberstein M (eds) Handbook of 
Evolutionary Thinking in the Sciences, Springer Netherlands, Dordrecht, pp $265-283$

Love AC (2017) Evo-Devo and the Structure(s) of Evolutionary Theory: A Different Kind of Challenge. In: Huneman P, Walsh D (eds) Challenging the modern synthesis: Adaptation, development, and inheritance, Oxford University Press

Love AC, Travisano M (2013) Microbes modeling ontogeny. Biology \& Philosophy 28:161-188

Margulis L (1970) Origin of Eukaryotic Cells: Evidence and Research Implications for a Theory of the Origin and Evolution of Microbial, Plant, and Animal Cells on the Precambrian Earth. Yale University Press

Margulis L (1981) Symbiosis in Cell Evolution: Microbial Communities in the Archean and Proterozoic Eons. Freeman

Margulis L, Sagan D (2004) Acquiring genomes: a theory of the origins of species. Recording for the Blind \& Dyslexic, Princeton, N.J.

McGraw MB (1946) Maturation of behavior. In: Manual of child psychology, John Wiley \& Sons Inc, Hoboken, NJ, US, pp 332-369

Merchant SS, Helmann JD (2012) Elemental Economy: Microbial Strategies for Optimizing Growth in the Face of Nutrient Limitation. In: Poole RK (ed) Advances in Microbial Physiology, vol 60, Academic Press, pp 91-210, DOI 10.1016/B978-0-12-398264-3.00002-4

Moczek AP, Sultan S, Foster S, Ledón-Rettig C, Dworkin I, Nijhout HF, Abouheif E, Pfennig DW (2011) The role of developmental plasticity in evolutionary innovation. Proceedings of the Royal Society B: Biological Sciences 278(1719):2705-2713, DOI 10.1098/rspb.2011.0971, publisher: Royal Society

Molenaar PCM, Huizenga HM, Nesselroade JR (2003) The Relationship Between the Structure of Interindividual and Intraindividual Variability: A Theoretical and Empirical Vindication of Developmental Systems Theory. In: Staudinger UM, Lindenberger U (eds) Understanding Human Development: Dialogues with Lifespan Psychology, Springer US, Boston, MA, pp 339-360

Molenaar PCM, Lerner RM, Newell KM (2013) Handbook of Developmental Systems Theory and Methodology. Guilford Publications, New York

Moss L (2001) Deconstructing the gene and reconstructing molecular developmental systems. In: Oyama S, Griffiths PE, Gray RD (eds) Cycles of contingency: developmental systems and evolution, MIT, Cambridge, Mass.; London, pp 85-98

Nijhout HF (1990) Problems And Paradigms: Metaphors and the role of genes in development. BioEssays 12(9):441-446, DOI 10.1002/bies.950120908, _eprint: https://onlinelibrary.wiley.com/doi/pdf/10.1002/bies.950120908

Odling-Smee FJ, Laland KN, Feldman MW (1996) Niche Construction. The American Naturalist 147(4):641-648, DOI 10.1086/285870, publisher: The University of Chicago Press

Odling-Smee FJ, Laland KN, Feldman MW (2003) Niche Construction: The Neglected Process in Evolution. Princeton University Press 
Okasha S (2006) Evolution and the Levels of Selection. Clarendon Press

O'Malley MA (2014) Philosophy of microbiology. Cambridge University Press, Cambridge, United Kingdom

O'Malley MA, Parke EC (2018) Microbes, mathematics, and models. Studies in History and Philosophy of Science Part A 72:1-10, DOI 10.1016/j.shpsa.2018.07.001

O'Malley MA, Parke EC (2020) Philosophy of Microbiology. The Stanford Encyclopedia of Philosophy URL https://plato.stanford.edu/archives/fall2020/entries/microbiology/

Oyama S (1985) The ontogeny of information: developmental systems and evolution, 2nd edn. Science and cultural theory, Duke University Press, Durham, N.C.

Oyama S (2000) Causal Democracy and Causal Contributions in Developmental Systems Theory. Philosophy of Science 67:S332-S347

Oyama S (2001) Terms in tension: what do you do when all the good words are taken? In: Oyama S, Griffiths PE, Gray RD (eds) Cycles of contingency: developmental systems and evolution, MIT, Cambridge, Mass.; London, pp $177-194$

Oyama S (2002) The Nurturing of Natures. In: Grunwald A, Gutmann M, Neumann-Held EM (eds) On Human Nature, Springer Berlin Heidelberg, Berlin, Heidelberg, pp 163-170

Oyama S, Griffiths PE, Gray RD (2001) Introduction: What is developmental systems theory? In: Oyama S, Griffiths PE, Gray RD (eds) Cycles of contingency: developmental systems and evolution, MIT, Cambridge, Mass.; London, pp 1-12

O'Malley MA, Powell R (2016) Major problems in evolutionary transitions: how a metabolic perspective can enrich our understanding of macroevolution. Biology \& Philosophy 31(2):159-189, DOI 10.1007/s10539-015-9513-z, URL https://doi.org/10.1007/s10539-015-9513-z

O'Malley MA, Travisano M, Velicer GJ, Bolker JA, Dykhuizen HEDE (2015) How Do Microbial Populations and Communities Function as Model Systems? The Quarterly Review of Biology 90(3):269-293, DOI 10.1086/682588, publisher: The University of Chicago Press

Pajares S, Ramos R (2019) Processes and Microorganisms Involved in the Marine Nitrogen Cycle: Knowledge and Gaps. Frontiers in Marine Science 6:739, DOI 10.3389/fmars.2019.00739, URL https://www.frontiersin.org/article/10.3389/fmars.2019.00739/full

Pigliucci M (1998) Developmental phenotypic plasticity: where internal programming meets the external environment. Current Opinion in Plant Biology 1(1):87-91, DOI 10.1016/s1369-5266(98)80133-7

Pigliucci M (2001) Phenotypic Plasticity: Beyond Nature and Nurture. JHU Press, google-Books-ID: JoCFupYhdNQC

Pigliucci M (2006) Phenotypic plasticity and evolution by genetic assimilation. Journal of Experimental Biology 209(12):2362-2367, DOI 10.1242/jeb.02070

Pigliucci M (2007) Do we need an extended evolutionary synthesis? Evolution 61(12):2743-2749, DOI 10.1111/j.1558-5646.2007.00246.x 
Pigliucci M, Schlichting CD (1997) On the Limits of Quantitative Genetics for the Study of Phenotypic Evolution. Acta Biotheoretica 45(2):143-160, DOI 10.1023/A:1000338223164

Pradeu T (2010) The Organism in Developmental Systems Theory. Biological Theory 5(3):216-222

Quammen D (2018) The Tangled Tree: A Radical New History of Life. Simon and Schuster

Richardson LA (2017) Evolving as a holobiont. PLOS Biology 15(2):e2002168, DOI 10.1371/journal.pbio.2002168

Robert JS (2004) Embryology, Epigenesis and Evolution: Taking Development Seriously. Cambridge University Press

Robert JS, Hall BK, Olson WM (2001) Bridging the gap between developmental systems theory and evolutionary developmental biology. BioEssays 23(10):954-962, DOI 10.1002/bies.1136

Rousk J, Bengtson P (2014) Microbial regulation of global biogeochemical cycles. Frontiers in Microbiology 5, DOI 10.3389/fmicb.2014.00103

Sagan L (1967) On the Origin of Mitosing Cells. Journal of Theoretical Biology $14: 225-274$

Schneirla TC (1956) Interrelationships of the "innate" and the "acquired" in instinctive behavior. In: Sellars R, McGill V, Farber M (eds) Philosophy for the future, Macmillan, New York

Sessions AL, Doughty DM, Welander PV, Summons RE, Newman DK (2009) The Continuing Puzzle of the Great Oxidation Event. Current Biology 19(14):R567-R574, DOI 10.1016/j.cub.2009.05.054

Shea N (2011) Developmental Systems Theory Formulated as a Claim about Inherited Representations. Philosophy of Science 78(1):60-82, DOI $10.1086 / 658110$

Skillings D (2016) Holobionts and the ecology of organisms: Multi-species communities or integrated individuals? Biology \& Philosophy 31(6):875-892, DOI 10.1007/s10539-016-9544-0

Sniegowski PD, Gerrish PJ, Lenski RE (1997) Evolution of high mutation rates in experimental populations of E. coli. Nature 387(6634):703-705, DOI 10.1038/42701, URL https://www.nature.com/articles/42701, number: 6634 Publisher: Nature Publishing Group

Sterelny K (2001) Niche constrution, developmental systems, and the extended replicator. In: Oyama S, Griffiths PE, Gray RD (eds) Cycles of contingency: developmental systems and evolution, MIT, Cambridge, Mass.; London, pp 333-350

Sterelny K, Kitcher P (1988) The Return of the Gene. The Journal of Philosophy DOI 10.2307/2026953, issue: 7 Pages: 339-361 Volume: 85

Sterelny K, Smith KC, Dickison M (1996) The extended replicator. Biology and Philosophy 11(3):377-403, DOI 10.1007/BF00128788

Stotz K (2008) The Ingredients for a Postgenomic Synthesis of Nature and Nurture. Philosophical Psychology 21(3):359-381, DOI $10.1080 / 09515080802200981$ 
Stotz K (2010) Human nature and cognitive-developmental niche construction. Phenomenology and the Cognitive Sciences 9(4):483-501, DOI 10.1007/s11097-010-9178-7

Taylor MJ, Bordenstein SR, Slatko B (2018) Microbe Profile: Wolbachia: a sex selector, a viral protector and a target to treat filarial nematodes. Microbiology 164(11):1345-1347, DOI 10.1099/mic.0.000724

Waddington $\mathrm{CH}$ (1941) Evolution of Developmental Systems. Nature 147(3717):108-110, DOI 10.1038/147108a0

Waddington CH (1942) The Epigenotype. Endeavour pp 18-20, DOI $10.1093 / \mathrm{ije} /$ dyr184

Watkins A (2021a) The Epistemic Value of the Living Fossils Concept. Philosophy of Science DOI 10.1086/714875

Watkins A (2021b) Testing for Phenotypic Plasticity. Philosophy, Theory, and Practice in Biology 13:1-23, DOI 10.3998/ptpbio.16039257.0013.003

West-Eberhard MJ (2003) Developmental Plasticity and Evolution. Oxford University Press

Wimsatt WC (2001) Generative entrenchment and the developmental systems approach in evolutionary processes. In: Oyama S, Griffiths PE, Gray RD (eds) Cycles of contingency: developmental systems and evolution, MIT, Cambridge, Mass.; London, pp 219-238

Woese CR, Fox GE (1977) Phylogenetic structure of the prokaryotic domain: The primary kingdoms. Proceedings of the National Academy of Sciences 74(11):5088-5090, DOI 10.1073/pnas.74.11.5088, URL https://www.pnas.org/content/74/11/5088, publisher: National Academy of Sciences Section: PNAS Classic Article

Woese CR, Magrum LJ, Fox GE (1978) Archaebacteria. Journal of Molecular Evolution 11(3):245-252, DOI 10.1007/BF01734485, URL https://doi.org/10.1007/BF01734485

Woese CR, Kandler O, Wheelis ML (1990) Towards a natural system of organisms: proposal for the domains Archaea, Bacteria, and Eucarya. Proceedings of the National Academy of Sciences 87(12):4576-4579, DOI 10.1073/pnas.87.12.4576, URL https://www.pnas.org/content/87/12/4576, publisher: National Academy of Sciences Section: Research Article

Wohlwill JF (1973) The study of behavioral development. The study of behavioral development, Academic Press, Oxford, England 